Article

\title{
Indoor Air Quality Assessment and Study of Different VOC Contributions within a School in Taranto City, South of Italy
}

\author{
Annalisa Marzocca ${ }^{1}$, Alessia Di Gilio ${ }^{1,2}$, Genoveffa Farella ${ }^{3}$, Roberto Giua ${ }^{1}$ and \\ Gianluigi de Gennaro ${ }^{1,2, *}$ \\ 1 Regional Agency for Environmental Protection and Prevention of the Puglia (ARPA Puglia), Corso Trieste, \\ 27, 70126 Bari, Italy; a.marzocca@arpa.puglia.it (A.M.); alessia.digilio@uniba.it (A.D.G.); \\ r.giua@arpa.puglia.it (R.G.) \\ 2 Department of Biology University of Bari, via Orabona, 4, 70126 Bari, Italy \\ 3 Department of Chemistry, University of Bari, via Orabona, 4, 70126 Bari, Italy; jennyfarella@gmail.com \\ * Correspondence: gianluigi.degennaro@uniba.it or g.degennaro@arpa.puglia.it
}

Academic Editors: Ki-Hyun Kim and Abderrahim Lakhouit

Received: 31 December 2016; Accepted: 2 March 2017; Published: 10 March 2017

\begin{abstract}
Children spend a large amount of time in school environments and when Indoor Air Quality (IAQ) is poor, comfort, productivity and learning performances may be affected. The aim of the present study is to characterize IAQ in a primary school located in Taranto city (south of Italy). Because of the proximity of a large industrial complex to the urban settlement, this district is one of the areas identified as being at high environmental risk in Italy. The study carried out simultaneous monitoring of indoor and outdoor Volatile Organic Compounds (VOC) concentrations and assessed different pollutants' contributions on the IAQ of the investigated site. A screening study of VOC and determination of Benzene, Toluene, Ethylbenzene, Xylenes (BTEX), sampled with Radiello ${ }^{\circledR}$ diffusive samplers suitable for thermal desorption, were carried out in three classrooms, in the corridor and in the yard of the school building. Simultaneously, Total VOC (TVOC) concentration was measured by means of real-time monitoring, in order to study the activation of sources during the monitored days. The analysis results showed a prevalent indoor contribution for all VOC except for BTEX which presented similar concentrations in indoor and outdoor air. Among the determined VOC, Terpenes and 2-butohxyethanol were shown to be an indoor source, the latter being the indoor pollutant with the highest concentration.
\end{abstract}

Keywords: IAQ; indoor/outdoor ratio; real-time monitoring; industrial area

\section{Introduction}

Indoor pollution may have a significant bearing on health considering that people spend the majority of their time indoors, so understanding indoor exposures and the role of outdoor air pollution in shaping such exposures is a priority issue [1].

Among the indoor environments, school buildings are to be the object of attention, because children are more sensitive to pollutants than adults and they spend large amounts of time in the school environment [2-4]. Additionally, indoor air quality in school can significantly influence the efficiency of student learning processes and performances, determining an association between school absenteeism and poor building conditions [5-7].

Pollutants in school buildings can have different emission sources, operating both inside and outside the classroom. In these spaces, a number of factors influence good air quality including the number of inhabitants, activities conducted inside the classrooms and insufficient ventilation, 
aggravated by the poor construction and maintenance of many school buildings [8,9]. Among pollutants, volatile organic compounds (VOC) are considered important parameters for the assessment of air quality in indoor and outdoor environments because of their ubiquitous presence and their significant impact on the environment and human health $[3,10]$.

A modest number of studies have examined VOC in school's indoor air [8,11-13]. Usually the organic compounds in these environments tend to be lower in the spacious and well ventilated classrooms with a low occupancy ratio [14], whereas accumulation of pollutants occurs when doors and windows remain closed for long periods of time in order to maintain thermal comfort, especially in winter. In addition to this, children are involved in different types of art and craft activities, using glue and paints that may increase the level of VOC in the classroom. Moreover, the use of cleaning products inside the school environment is also a possible source of VOC together with the intrusion of outdoor pollutants, especially if the school is located in an urban environment. The traffic, the distance from the road and the presence of industrial facilities in the neighborhoods, together with some meteorological factors (such as wind direction and speed), could affect the interior air quality. Moreover, atmospheric dispersion in the vicinity of buildings determines the concentration patterns near the buildings and on the building surfaces, and thus the infiltration of outdoor pollutants inside the buildings [15]. The ventilation rate in school classrooms has a large effect as it can lead to the intrusion of outdoor pollutants, especially in urban or industrial polluted areas. The Indoor-to-Outdoor concentration ratio (I/O) may be used to assess the relationship between indoor and outdoor VOC contributions.

The aim of the present study is the assessment of the indoor air quality in a primary school, located in close proximity to a high-impact industrial site such as the industrial area of Taranto (south of Italy), which is considered one of the areas of high environmental risk included in the list of polluted sites of national interest. In fact, the industrial zone of Taranto is characterized by a multiplicity of high-impact industrial activities, including the largest steel plant of Europe, a refinery, a quarry, a cement plant, a composting plant, a port in which liquid and solid bulk are handled, as well as containers.

The study carried out simultaneous monitoring of indoor and outdoor VOC concentration and assessed the influence of outdoor emissions on the IAQ of the investigated site. A screening study of VOC and determination of Benzene, Toluene, Ethylbenzene, Xylenes (BTEX) (VOC were carried out in three classrooms, in the corridor and in the yard of the school building. Simultaneously, total volatile organic compounds (TVOC) concentration was measured by means of real-time monitoring, in order to study the activation of sources during the monitored days. Data collected in indoor environments were compared with outdoor data to evaluate the different indoor/outdoor contributions and to study the intrusion phenomena.

\section{Materials and Methods}

The school selected is a naturally ventilated primary school located in a central position near three air quality stations (Orsini-Ilva network; Machiavelli network; Archimede-Regional network ARPA). Three classrooms were chosen on the basis of similar characteristics, such as level in the school building, surface, volume, number of windows, windows structure, number of occupants, activities, internal covering including flooring, wall and ceiling. Furthermore, measurements were carried out in the corridor of the school building and outdoors, in the yard of the school. Classrooms were occupied during school days for a total of $30 \mathrm{~h}$ during each monitored period (one week). They were unoccupied during afternoons, evenings, nights and Sunday. Class started at 08:00 and finished at 13:00.

A screening study of VOC and determination of BTEX, sampled with diffusive samplers suitable for thermal desorption, was carried out in the chosen sites. Two samplers were exposed for two monitoring periods (one week each) in all chosen environments. The indoor samplers were positioned at a height of about $1.5 \mathrm{~m}$ above the floor and at a distance that exceeded $1 \mathrm{~m}$ from windows or doors. Outdoor VOC measurements were collected for two weeks (two samplers for each monitoring period) at heights of about $2 \mathrm{~m}$ above the ground [16,17]. 
VOC monitoring was performed with Radiello ${ }^{\circledR}$ diffusive samplers (Fondazione Salvatore Maugeri, Padova, Italy) suitable for thermal desorption. The system consists of a cylindrical adsorbing cartridge made up of a stainless-steel net cylinder with 100 mesh, and an external diameter of $4.8 \mathrm{~mm}$, containing $350 \mathrm{mg}$ of Carbograph 4 (35-50 mesh). The cartridge was housed coaxially inside a cylindrical diffusive body of polycarbonate and microporous polyethylene. Before sampling, the cartridges were conditioned and analyzed to verify blank levels $[18,19]$. Each sampler was exposed for the periods indicated and then brought to the laboratory for analysis closed in a sealed glass tube. The desorption was carried out using a two-stage thermal desorber (Markes International Ltd., Unity ${ }^{\mathrm{TM}}$, Llantrisant, UK) equipped with an autosampler (mod. ULTRA ${ }^{\mathrm{TM}}$ TD, Markes International Inc., Cincinnati, OH, USA) which was provided with 100 positions and coupled with a gas chromatograph (Agilent GC-6890 PLUS, Loveland, CO, USA) and a mass selective detector (Agilent MS-5973N). In the first stage of desorption, the analytes were desorbed from the sample tube and refocused into a cold trap; then they were desorbed from the trap and carried into the gas chromatograph column [18-20].

Standard solutions were prepared by injecting successive dilution in methanol of a VOC standard mixture at $2000 \mu \mathrm{g} / \mathrm{mL}$ (Cus-5997 Ultra Scientific, Bologna, Italy). A calibration curve was prepared by injecting $1 \mu \mathrm{L}$ of the standard solution into a tube; the spiked adsorbent tubes were then thermally desorbed in the same conditions of time, gas flow and split ratio as the samples. The sampling rates $(Q)$, supplied by the manufacturer, were a function of the diffusive coefficient $(D)$, which was the thermodynamic property of each chemical substance. To calculate the real concentration (C) of compounds in the atmosphere by GC quantification of analytes' mass $(m)$, the sampling rates $(\mathrm{Q})$ were used. When $\mathrm{m}$ was expressed in $\mu \mathrm{g}$, the sampling period in minutes and $\mathrm{C}$ in $\mu \mathrm{g} / \mathrm{L}, \mathrm{Q}$ was expressed in L/min [21]. The assessment of the performance and reliability of the indoor monitoring methodology to determine VOC concentrations using radial diffusive samplers for thermal desorption was presented in previous works [18-20]. In particular, the repeatability of the analysis for thermal desorption, the complete desorption of the cartridges, the limit of detection (LOD), and the limits of quantification (LOQ) were evaluated [19]. The results showed that the RSD\% was less than 10 for all compounds. The percentage recovery was higher than $95 \%$, confirming the high method reliability for VOC analysis.

Simultaneously, real-time monitoring of TVOC was carried out in order to study the activation of sources during the monitored days and the possible intrusion of outdoor VOC in indoor air.

The high temporal resolution monitoring of TVOC was performed in the sampling sites with Corvus (Ion Science Ltd., Cambridge, UK) which uses Photo-ionization technology to detect a large range of VOC. Corvus was factory calibrated against isobutylene and thus the concentration of TVOC was equivalent to this gas.

\section{Results and Discussion}

The VOC concentrations measured (minimum, maximum and mean value), at all monitored sites during whole sampling period (two weeks), were presented in Table 1. Although the monitored school was located near a large industrial implant, in one of the district areas identified at high environmental risk in Italy, low outdoor concentrations were detected if compared with outdoor VOC concentrations found in similar industrial areas in the world [22-26]. These findings were probably due to the fact that the outdoor samplers were positioned in the yard of the school (according to UNI EN ISO 16000-1), so that detected concentrations were representative of the air in proximity of the indoor site. Outdoor sites were probably less affected by vehicular traffic and industrial emissions depending on the site-specific characteristics of the building and in particular of its yard. In fact, the court of the school is enclosed and has a little recess which isolated the entire school building from the closest industrial area. 
Table 1. Volatile Organic Compounds concentrations measured in indoor and outdoor monitoring sites (minimum, maximum and mean value).

\begin{tabular}{|c|c|c|c|c|c|c|c|c|c|c|c|c|c|c|c|}
\hline \multirow{3}{*}{ Compound } & \multicolumn{15}{|c|}{ Concentration $\left(\mu \mathrm{g} / \mathrm{m}^{3}\right)$} \\
\hline & \multicolumn{3}{|c|}{ Classroom 5C } & \multicolumn{3}{|c|}{ Classroom 5D } & \multicolumn{3}{|c|}{ Classroom 4C } & \multicolumn{3}{|c|}{ Corridor } & \multicolumn{3}{|c|}{ Outdoor } \\
\hline & Min & Max & Mean & Min & Max & Mean & Min & Max & Mean & Min & Max & Mean & Min & Max & Mean \\
\hline Methyl-tert-butil- etere & 0.33 & 0.82 & 0.53 & 0.28 & 0.86 & 0.61 & 0.14 & 0.80 & 0.47 & 0.32 & 0.68 & 0.50 & 0.65 & 0.96 & 0.85 \\
\hline Benzene & 0.41 & 0.53 & 0.48 & 0.38 & 0.61 & 0.50 & 0.12 & 0.44 & 0.29 & 0.38 & 0.50 & 0.45 & 0.59 & 0.84 & 0.67 \\
\hline Toluene & 1.34 & 1.78 & 1.54 & 1.51 & 1.88 & 1.66 & 1.37 & 1.49 & 1.45 & 1.31 & 1.69 & 1.52 & 1.54 & 1.90 & 1.64 \\
\hline N-Octane & 0.21 & 0.56 & 0.40 & 0.11 & 1.25 & 0.61 & 0.23 & 0.36 & 0.26 & 0.21 & 0.35 & 0.28 & 0.20 & 0.35 & 0.26 \\
\hline Tetrachloroethylene & 0.07 & 0.11 & 0.09 & 0.07 & 0.12 & 0.09 & 0.07 & 0.09 & 0.08 & 0.07 & 0.11 & 0.09 & 0.08 & 0.14 & 0.10 \\
\hline Ethylbenzene & 0.48 & 1.18 & 0.80 & 0.41 & 1.40 & 0.76 & 0.43 & 1.18 & 0.71 & 0.42 & 1.13 & 0.77 & 0.37 & 1.23 & 0.76 \\
\hline M/p-Xylenes & 0.85 & 1.74 & 1.27 & 0.79 & 1.64 & 1.21 & 0.89 & 2.20 & 1.44 & 0.81 & 1.45 & 1.14 & 0.78 & 1.54 & 1.14 \\
\hline Styrene & 0.04 & 0.36 & 0.18 & 0.06 & 0.25 & 0.17 & $<0.03 *$ & 0.43 & 0.17 & 0.04 & 0.23 & 0.13 & 0.13 & 0.17 & 0.15 \\
\hline$O$-Xylene & 0.76 & 1.90 & 1.30 & 0.60 & 2.00 & 1.21 & 0.75 & 2.63 & 1.54 & 0.59 & 1.72 & 1.07 & 0.43 & 2.03 & 1.08 \\
\hline$N$-nonane & 0.17 & 1.13 & 0.61 & 0.27 & 2.89 & 1.57 & 0.88 & 1.06 & 0.58 & 0.20 & 1.17 & 0.67 & 0.14 & 0.60 & 0.34 \\
\hline 2-Butoxyethanol & 27.92 & 35.55 & 31.60 & 33.32 & 46.43 & 36.31 & 23.10 & 36.59 & 30.21 & 28.61 & 33.36 & 30.30 & $<0.03 *$ & 1.37 & 0.71 \\
\hline Alpha pinene & 0.33 & 0.99 & 0.72 & 0.73 & 1.51 & 1.07 & 0.88 & 1.27 & 1.02 & 0.30 & 0.98 & 0.60 & $<0.03 *$ & 0.15 & 0.06 \\
\hline Camphene & 1.67 & 3.35 & 2.54 & 1.57 & 3.04 & 2.43 & 0.90 & 2.14 & 1.38 & 4.82 & 6.02 & 5.30 & 0.06 & 0.15 & 0.10 \\
\hline 1,2,4-Trimethylbenzene & 0.56 & 4.55 & 2.12 & 0.51 & 2.98 & 1.69 & 0.59 & 5.80 & 2.71 & 0.63 & 2.70 & 1.67 & 0.48 & 4.09 & 2.29 \\
\hline$N$-Decane & 0.13 & 1.65 & 0.85 & 0.23 & 2.81 & 1.51 & 0.15 & 1.61 & 0.86 & 0.19 & 2.04 & 1.08 & 0.12 & 0.62 & 0.37 \\
\hline Limonene & 1.14 & 3.75 & 2.19 & 1.33 & 4.53 & 2.94 & 3.65 & 7.98 & 5.66 & 1.65 & 3.56 & 2.57 & $<0.05^{*}$ & 0.24 & 0.08 \\
\hline
\end{tabular}


In order to understand whether VOC sources were located in indoor or in outdoor air, the indoor concentration values for each pollutant were plotted against the corresponding outdoor value and five different I/O ranges were defined [8]. I/O ratios are commonly used to highlight the presence of important indoor emission sources. Ratios greater than a defined threshold value indicated the predominance of indoor contributions over outdoor contributions.

Figures 1-5 show that indoor concentrations of Benzene and substituted benzenes (during the first and the second monitoring campaign) are due to the input/intrusion of VOC from outdoor areas in most of the classrooms. Indeed, benzene and substituted benzenes are known as markers of vehicular traffic emissions [27].

Figure 1 shows that during both monitoring periods, all indoor sites present $\mathrm{I} / \mathrm{O}$ ratios of Benzene in the range $0.5<\mathrm{I} / \mathrm{O}<2$ except for the classroom $4 \mathrm{C}$ during the second week which presents an $\mathrm{I} / \mathrm{O}$ ratio in the range $0.2<\mathrm{I} / \mathrm{O}<0.5$. The indoor concentrations for BTEX were similar to outdoor ones; in fact, the I/O ratio value falls in the range $0.5<\mathrm{I} / \mathrm{O}<2$. This is a demonstration that the $\mathrm{I} / \mathrm{O}$ ratio does not provide sufficient values for highlighting critical issues, especially when values ranged from 0.5 to 2 , in which case it is important to analyze the concentration levels. The I/O ratio can be used to highlight the presence of important indoor emission sources or outdoor emission sources when it is very high $(\mathrm{I} / \mathrm{O}>5)$ or very low $(\mathrm{I} / \mathrm{O}<0.2)$ respectively.

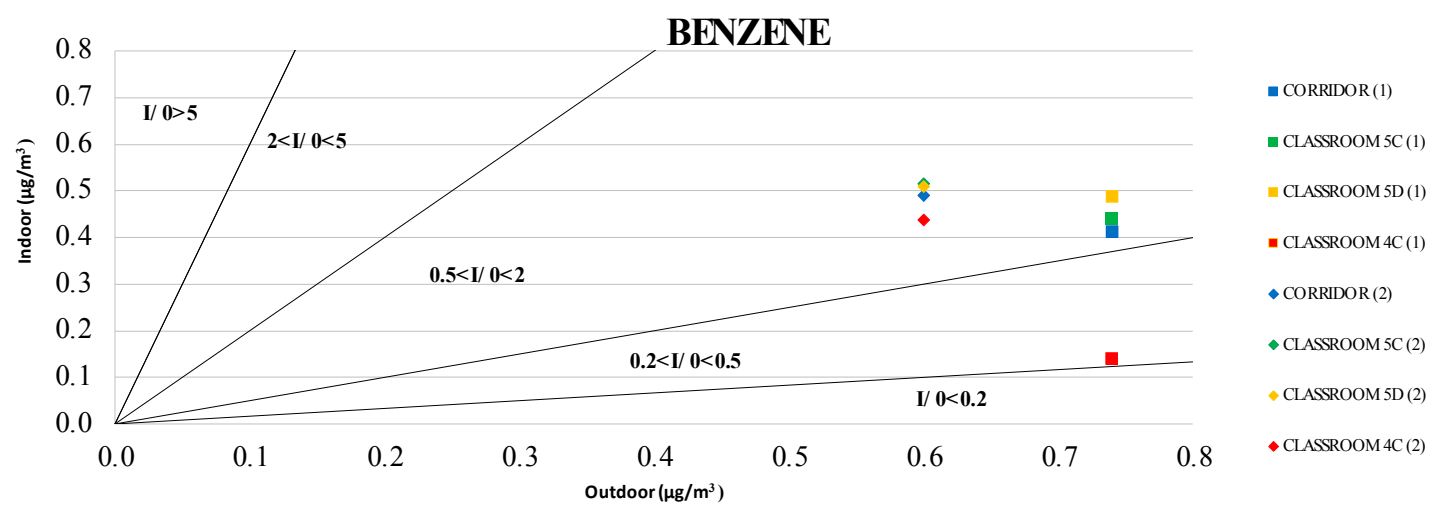

Figure 1. Benzene indoor concentrations against outdoor concentrations in all monitored sites during the first (1) and the second (2) monitoring periods.

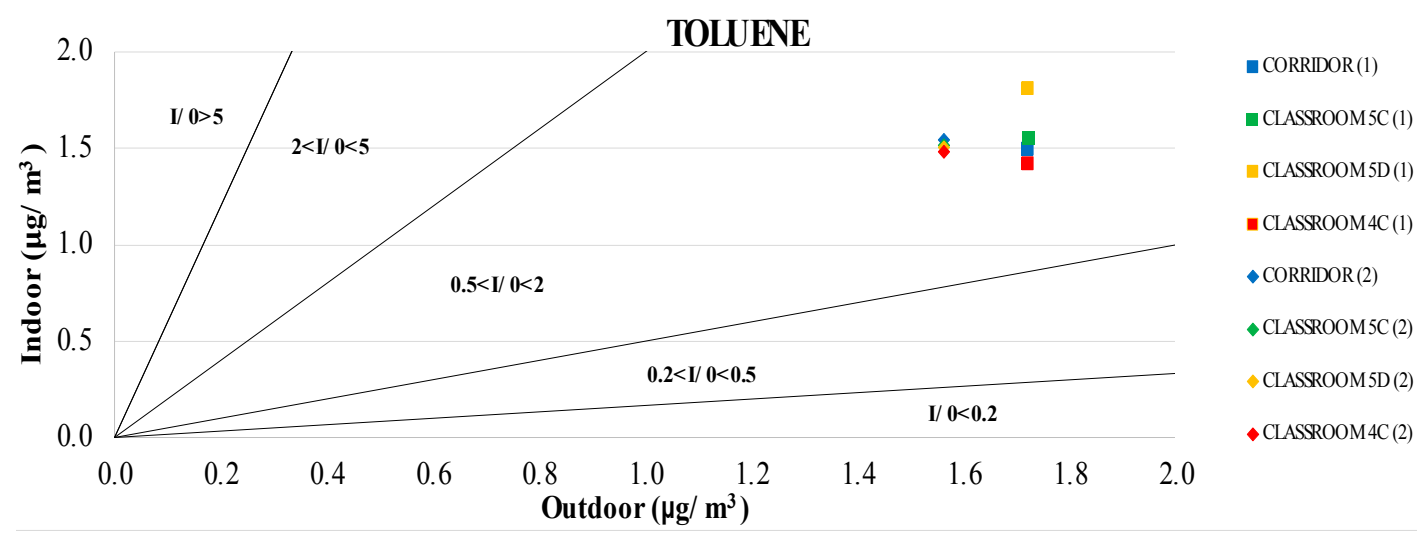

Figure 2. Toluene indoor concentrations against outdoor concentrations in all monitored sites during the first (1) and the second (2) monitoring periods. 


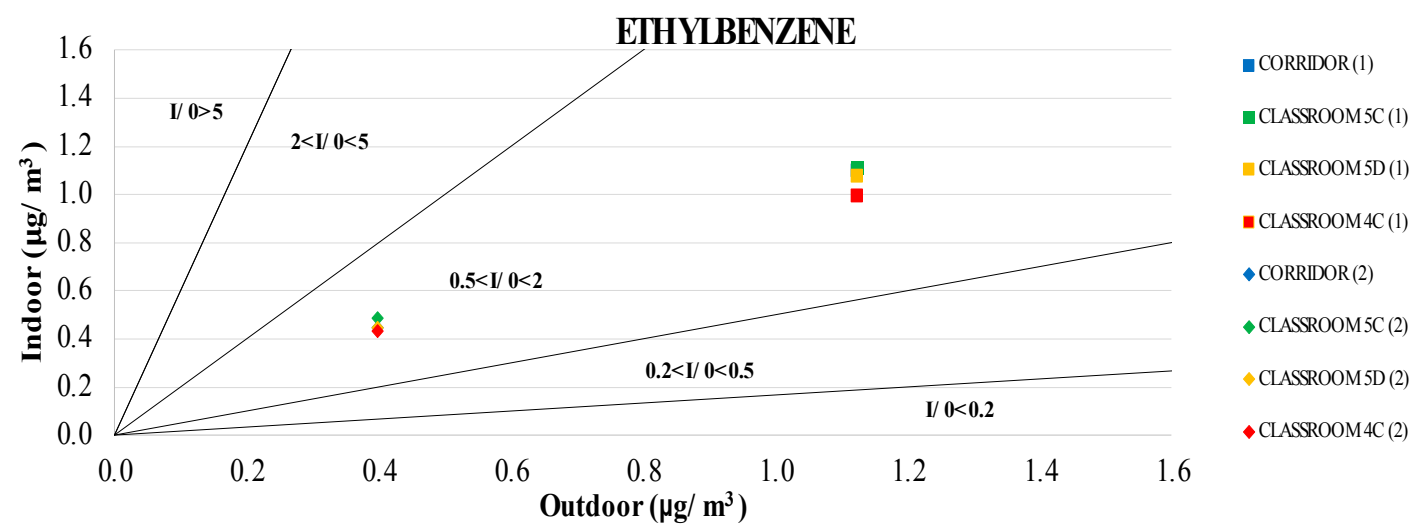

Figure 3. Ethylbenzene indoor concentrations against outdoor concentrations in all monitored sites during the first (1) and the second (2) monitoring periods.

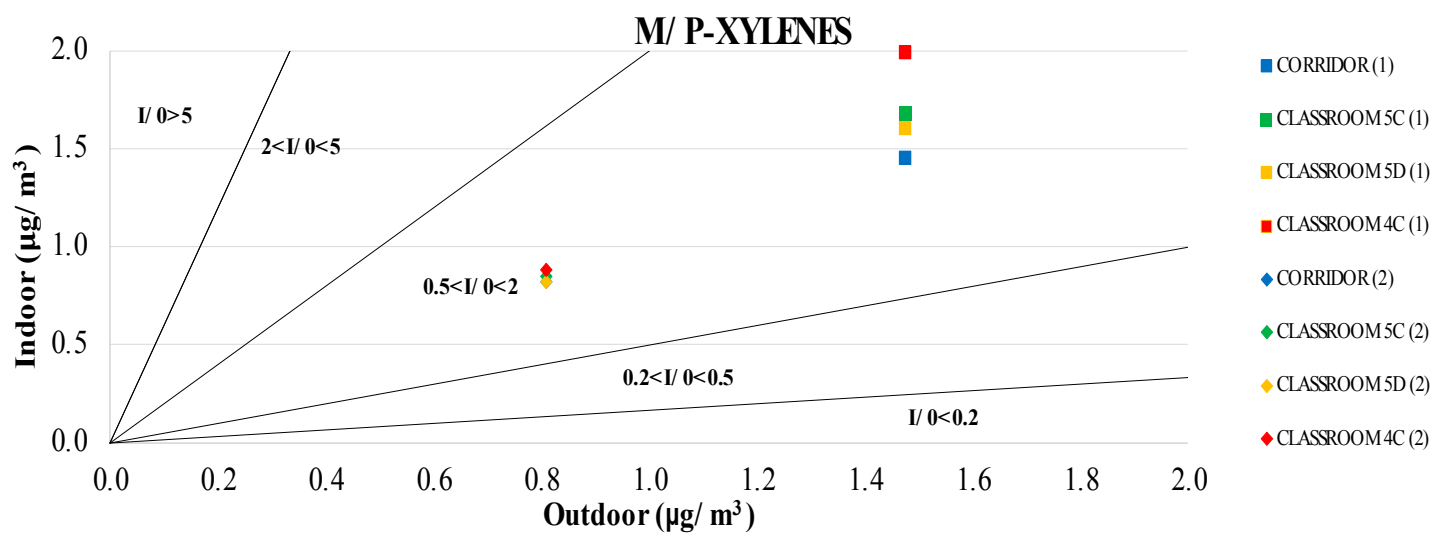

Figure 4. M, P, Xylenes indoor concentrations against outdoor concentrations in all monitored sites during the first (1) and the second (2) monitoring periods.

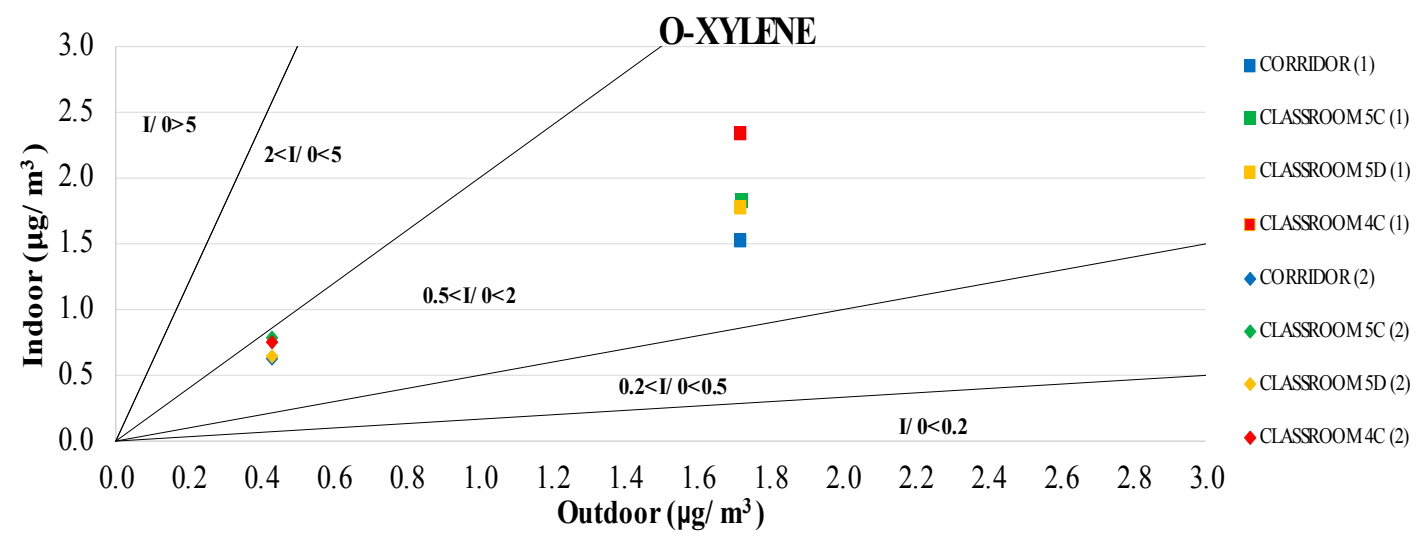

Figure 5. O-xylene indoor concentrations against outdoor concentrations in all monitored sites during the first (1) and the second (2) monitoring periods.

Figures 6 and 7 show indoor concentrations against outdoor concentrations for 2-butoxyethanol and limonene. For these pollutants, indoor average concentrations were respectively 30 and 5.9 times higher than outdoor ones.

2-Butoxyethanol, limonene and terpenes, in general, were the most abundant compounds in indoor air. Terpenes are odorous compounds mainly used to give pleasant fragrance in particular in cleaning products $[8,28-30]$. The high levels of 2-butoxyethanol in classrooms and in the corridor, were 
probably due to the fact that this compound is used as a solvent for many commercial products such as detergents, paints, adhesives, coatings, inks and products for personal care [31,32]. In particular, by reviewing the technical details of a range of cleaning products, it is present in percentages ranging between $2 \%$ and $20 \%$ in the degreaser and products for washing windows.

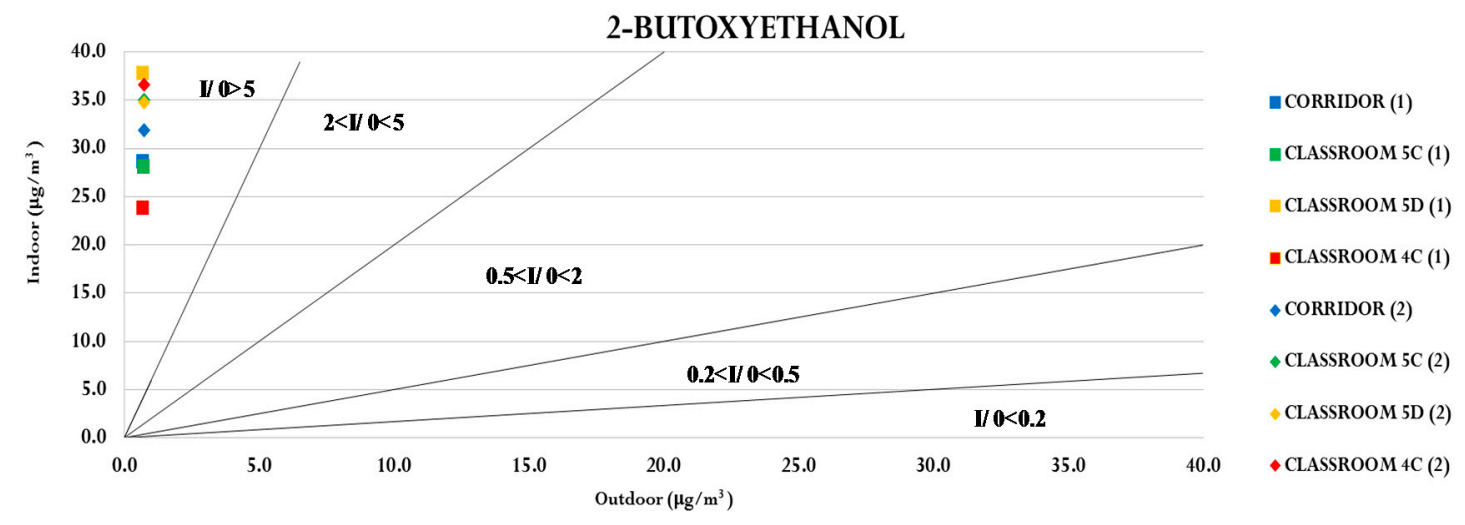

Figure 6. 2-Butoxyethanol indoor concentrations against outdoor concentrations in all monitored sites during the first (1) and the second (2) monitoring periods.

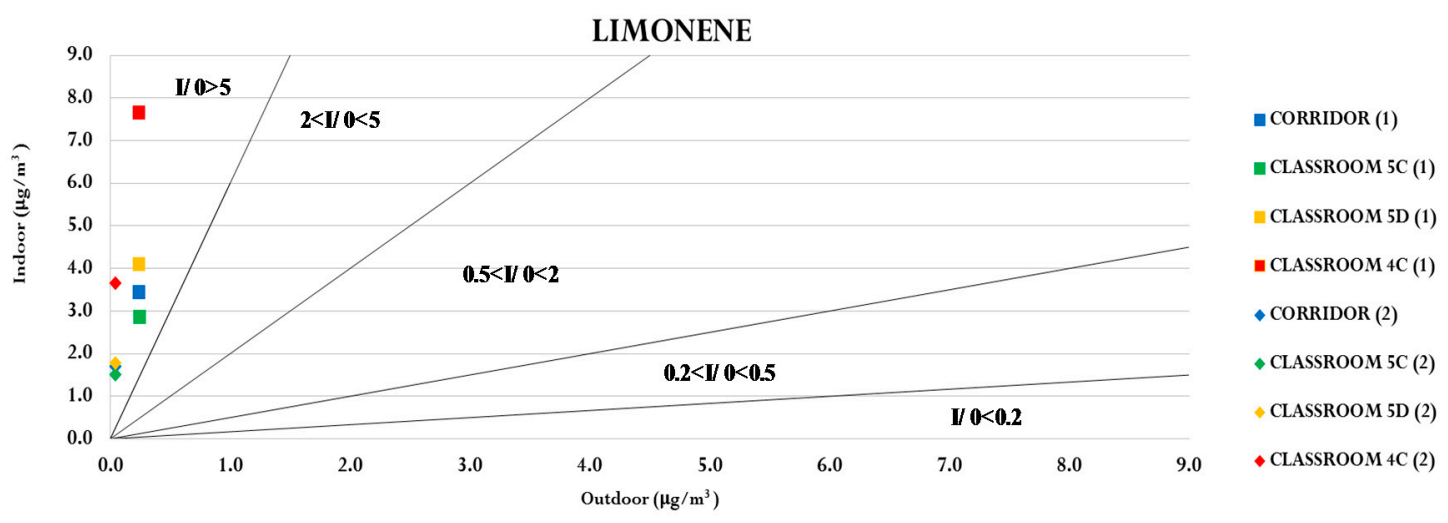

Figure 7. Limonene indoor concentrations against outdoor concentrations in all monitored sites during the first (1) and the second (2) monitoring periods.

In order to monitor the trend of TVOC concentration during school hours in the whole monitoring period, a high temporal resolution monitoring of Total Volatile Organic Compounds was also performed in the sampling sites. The detection of TVOC concentrations was carried out with Corvus (Ion Science Ltd., Cambridge, UK) which used Photo-ionization technology to detect a large range of VOC. This method can be useful to integrate the diffusive samplers' measurements value (a mean over the exposure periods-one week in this study) by identifying the trend of VOC concentration in different periods of the day over short time intervals-useful to find potential indoor sources.

Figure 8 shows the trend of TVOC concentrations during the sampling period.

The highest TVOC concentrations (ppm equivalent of isobutylene) in the monitored indoor sites were detected during cleaning activities, which occurred after the pupils leave and before the school closed (from 13:00). This confirms that cleaning activities were the most important source of indoor pollutants.

Table 2 shows a comparison of the indoor concentrations of selected VOC detected in this study with those obtained in studies conducted in other school microenvironments in other countries. As shown in the table, the VOC concentrations found at the school in Taranto City were in line with or above those of other studies conducted in the same condition (primary school monitored with diffusive samplers). 
Table 2. Indoor school concentrations $\left(\mu \mathrm{g} / \mathrm{m}^{3}\right)$ of selected VOC species in this, and in other studies. $\mathrm{a}=[11], \mathrm{b}=[12], \mathrm{c}=[13], \mathrm{d}=[8]$.

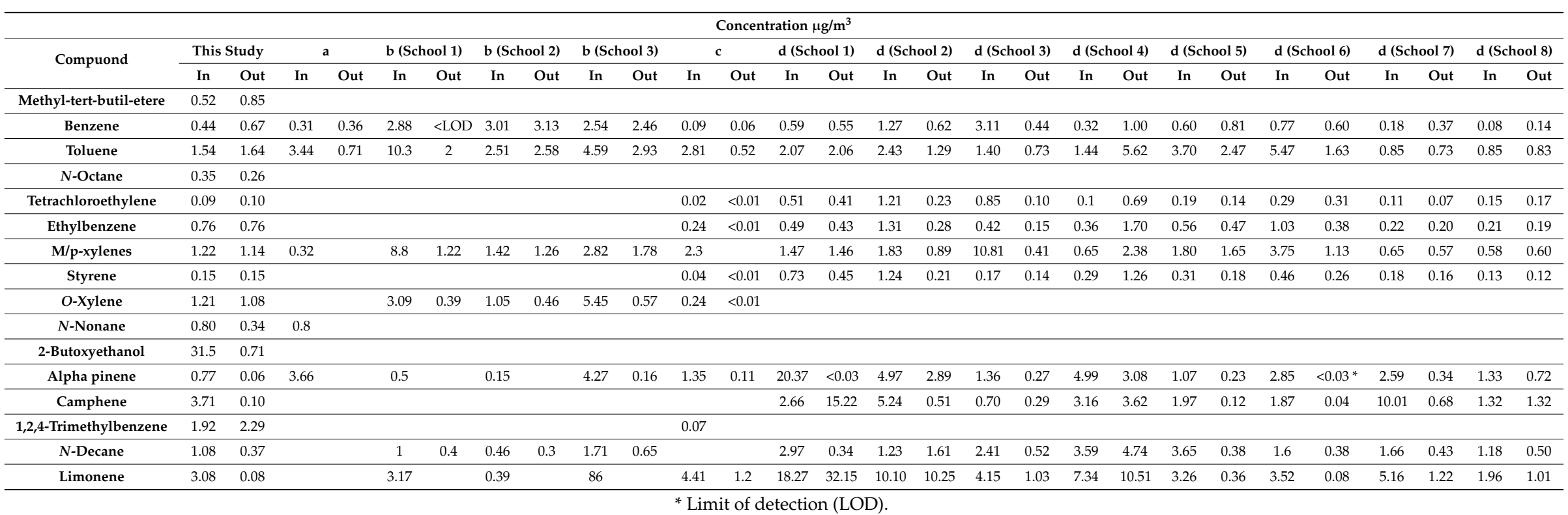




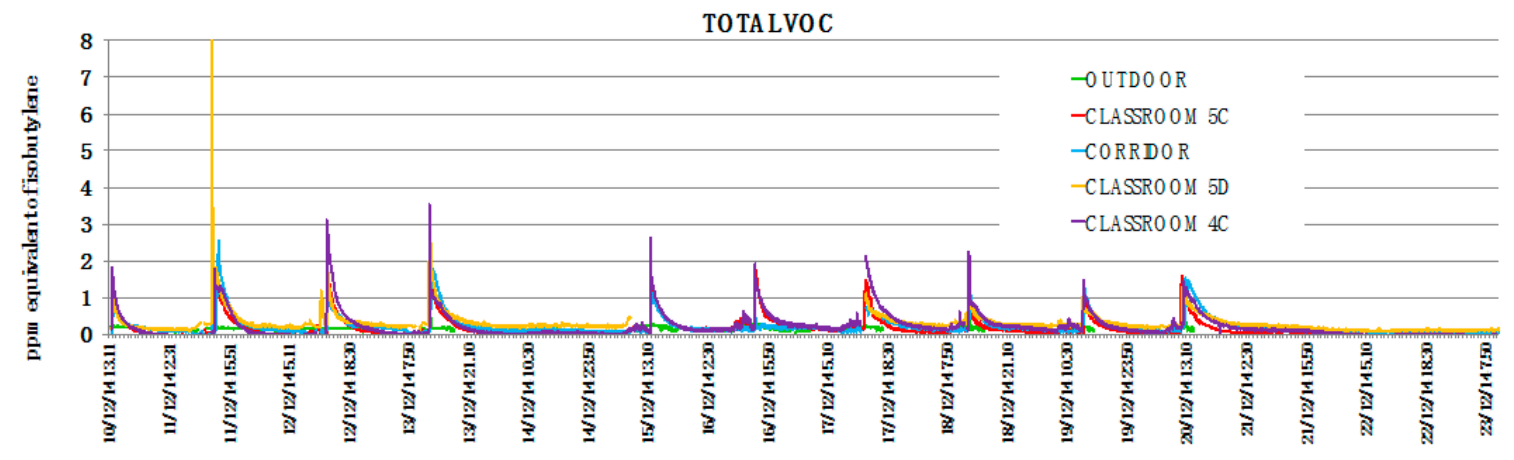

Figure 8. Trend of total volatile organic compounds (TVOC) concentration in all monitored sites for the entire sampling period.

\section{Conclusions}

The aim of this study was to assess the indoor air quality in a naturally ventilated school building by conducting a VOC screening monitoring campaign. The identification and quantification of VOC and the indoor/outdoor concentration plots allowed to detect the main emission sources. In particular, a significant indoor contribution by Terpenes and 2-butoxyethanol was found which presented the highest indoor concentrations. Despite the proximity of the school to the industrial area, the outdoor VOC concentrations were low in comparison to other studies conducted in the world in similar areas identified as being at high environmental risk. The use of high time resolution monitoring equipment facilitated the identification of the VOC emissions patterns of possible indoor sources and confirmed that the cleaning activities, occurring after the pupils leave, represents a critical issue for IAQ.

The present work represents a preliminary study and requires more measurements; in fact, analogous studies should be conducted in other schools, in particular when these are located near an industrial area, in order to give a precious tool for more efficient management with regards to mitigation actions.

Acknowledgments: Special appreciation goes to Dambruoso Paolo Rosario for the collaboration in sampling campaign. Annalisa Marzocca wrote the paper.

Author Contributions: This work is the result of the authors' commitment, starting from the idea and ending with its accomplishment. Particularly, each author contributed as follows: Annalisa Marzocca, Alessia Di Gilio, Gianluigi De Gennaro and Roberto Giua conceived and designed the sampling and the experiments; Genoveffa Farella analyzed the samples.

Conflicts of Interest: The authors declare no conflict of interest.

\section{References}

1. Ezzati, M. Indoor Air Pollution: Developing Countries. Int. Encycl. Public Health 2017. [CrossRef]

2. Faustman, E.M.; Silbernagel, S.M.; Fenske, R.A.; Burbacher, T.M.; Ponce, R.A. Mechanisms underlying children's susceptibility to environmental toxicants. Environ. Health. Perspect. 2000, 108, 13-21. [CrossRef] [PubMed]

3. Dambruoso, P.R.; de Gennaro, G.; Demarinis Loiotile, A.; Di Gilio, A.; Giuncato, P.; Marzocca, A.; Mazzone, A.; Palmisani, J.; Porcelli, F.; Tutino, M. School Air Quality: Pollutants, Monitoring and Toxicity; Pollutant Diseases, Remediation and Recycling-Volume 4 of the Series Environmental Chemistry for a Sustainable World; Springer: Berlin, Germany, 2013; pp. 1-44.

4. Rivas, I.; Viana, M.; Moreno, T.; Pandolfi, M.; Amato, F.; Reche, C.; Bouso, L.; Àlvarez-Pedrerol, M.; Alastuey, A.; Sunyer, J.; et al. Child exposure to indoor and outdoor air pollutants in schools in Barcelona, Spain. Environ. Int. 2014, 69, 200-212. [CrossRef] [PubMed]

5. Wargocki, P.; Wyon, D.P. Ten questions concerning thermal and indoor air quality effects on the performance of office work and schoolwork. Build. Environ. 2017, 112, 359e366. [CrossRef] 
6. Stafford, T.M. Indoor air quality and academic performance. J. Environ. Econ. Manag. 2015, 70, 34-50. [CrossRef]

7. Rosbach, J.T.M.; Vonk, M.; Duijm, F.; van Ginkel, J.T.; Gehring, U.; Brunekreef, B. A ventilation intervention study in classrooms to improve indoor air quality: The FRESH study. Environ. Health 2013, 12, 110. [CrossRef] [PubMed]

8. De Gennaro, G.; Farella, G.; Marzocca, A.; Mazzone, A.; Tutino, M. Indoor and Outdoor Monitoring of Volatile Organic Compounds in School Buildings: Indicators Based on Health Risk Assessment to Single out Critical Issues. Int. J. Environ. Res. Public Health 2013, 10, 6273-6291. [CrossRef] [PubMed]

9. Chithra, V.S.; Shiva Nagendra, S.M. Indoor air quality investigations in a naturally ventilated school building located close to an urban roadway in Chennai, India. Build. Environ. 2012, 54, 159-167. [CrossRef]

10. De Gennaro, G.; Dambruoso, P.R.; Demarinis Loiotile, A.; Di Gilio, A.; Giungato, P.; Marzocca, A.; Mazzone, A.; Palmisani, J.; Porcelli, F.; Tutino, M. Indoor air quality in schools. Environ. Chem. Lett. 2007, 12, 467-482. [CrossRef]

11. Pegas, P.N.; Nunes, T.; Alves, C.A.; Silva, J.R.; Vieira, S.L.A.; Caseiro, A.; Pio, C.A. Indoor and outdoor characterization of organic and inorganic compounds in city centre and suburban elementary schools of Aveiro, Portugal. Atmos. Environ. 2012, 55, 80e89. [CrossRef]

12. Pegas, P.N.; Evtyugina, M.G.; Alves, C.A.; Nunes, T.; Cerqueira, M.; Franchi, M.; Pio, C. Outdoor/indoor air quality in primary schools in Lisbon: A preliminary study. Quim. Nova 2010, 33, 1145-1149. [CrossRef]

13. Godwin, C.; Batterman, S. Indoor air quality in Michigan schools. Indoor Air 2007, 17, 109-121. [CrossRef] [PubMed]

14. Pegas, P.N.; Alves, C.A.; Evtyugina, M.G.; Nunes, T.; Cerqueira, M.; Franchi, M.; Pio, C.A.; Almeida, S.M.; Freitas, M.C. Indoor air quality in elementary schools of Lisbon in spring. Environ. Geochem. Health 2011, 33, 455e468. [CrossRef] [PubMed]

15. Santos, J.M.; Mavroidis, I.; Reis, N.C.; Pagel, E.C. Experimental investigation of outdoor and indoor mean concentrations and concentration fluctuations of pollutants. Atmos. Environ. 2011, 45, 6534-6545. [CrossRef]

16. ISO. ISO 16000-1: Indoor Air-Part 1: General Aspects of Sampling Strategy; ISO: Geneva, Switzerland, 2004.

17. ISO. ISO 16000-5: Indoor Air-Part 5: Sampling Strategy for Volatile Organic Compounds (VOCs); ISO: Geneva, Switzerland, 2007.

18. Bruno, P.; Caputi, M.; Caselli, M.; de Gennaro, G.; de Rienzo, M. Reliability of a BTEX radial diffusive sampler for thermal desorption. Atmos. Environ. 2005, 39, 1347-1355. [CrossRef]

19. Bruno, P.; Caselli, M.; de Gennaro, G.; Iacobellis, S.; Tutino, M. Monitoring of volatile organic compounds in non-residential indoor environments. Indoor Air 2008, 18, 250-256. [CrossRef] [PubMed]

20. ISO. ISO 16017-2: Indoor, Ambient and Workplace Air-Sampling and Analysis of Volatile Organic Compounds by Sorbent Tube/Thermal Desorption/Capillary Gas Chromatography_Part 2: Diffusive Sampling; ISO: Geneva, Switzerland, 2003.

21. Radiello. Available online: http://www.radiello.com/english/index_en.htmlS (accessed on 10 December 2016).

22. Cetin, E.; Odabasi, M.; Seyfioglu, R. Ambient volatile organic compound (VOC) concentrations around a petrochemical complex and a petroleum refinery. Sci. Total Environ. 2003, 312, 103-112. [CrossRef]

23. Kalabokas, P.D.; Hatzaianestis, J.; Bartzis, J.G.; Papagiannakopoulos, P. Atmospheric concentrations of saturated and aromatic hydrocarbons around a Greek oil refinery. Atmos. Environ. 2001, 35, 2545-2555. [CrossRef]

24. Lin, T.Y.; Sree, U.; Tseng, S.H.; Hwa Chiu, K.; Wu, C.H.; Lo, J.G. Volatile organic compound concentrations in ambient air of Kaohsiung petroleum refinery in Taiwan. Atmos. Environ. 2004, 38, 4111-4122. [CrossRef]

25. Bruno, P.; Caselli, M.; de Gennaro, G.; de Gennaro, L.; Tutino, M. High spatial resolution monitoring of benzene and toluene in the Urban Area of Taranto (Italy). J. Atmos. Chem. 2006, 54, 177-187. [CrossRef]

26. Tiwari, V.; Hanai, Y.; and Masunaga, S. Ambient levels of volatile organic compounds in the vicinity of petrochemical industrial area of Yokohama, Japan. Air Qual. Atmos. Health 2010, 3, 65-75. [CrossRef] [PubMed]

27. Caselli, M.; de Gennaro, G.; Marzocca, A.; Trizio, L.; Tutino, M. Assessment of the impact of the vehicular traffic on BTEX concentration in ring roads in urban areas of Bari (Italy). Chemosphere 2010, 81, 306-311. [CrossRef] [PubMed] 
28. Scorecard's Data Sources—Good Guide. Available online: http://scorecard.goodguide.com/about/txt/ data.html (accessed on 9 December 2016).

29. Nazaroff, W.W.; Weschler, C.J. Cleaning products and air fresheners: Exposure to primary and secondary air pollutants. Atmos. Environ. 2004, 38, 2841-2865. [CrossRef]

30. De Gennaro, G.; Amodio, M.; Dambruoso, P.R.; de Gennaro, L.; Demarinis Loiotile, A.; Marzocca, A.; Stasi, F.; Trizio, L.; tutino, M. Indoor air quality (IAQ) assessment in a multistorey shopping mall by high-spatial-resolution monitoring of volatile organic compounds (VOC). Environ. Sci. Pollut. Res. Int. 2014, 21, 13186-13195.

31. Zhu, J.; Cao, X.L.; Beauchamp, R. Determination of 2-butoxyethanol emissions from selected consumer products and its application in assessment of inhalation exposure associated with cleaning tasks. Environ. Int. 2001, 26, 589-597. [CrossRef]

32. National Institute of Building Sciences. Reviewing and Refocusing on IAQ in Schools; National Institute of Building Sciences: Washington, DC, USA, 2006.

(C) 2017 by the authors. Licensee MDPI, Basel, Switzerland. This article is an open access article distributed under the terms and conditions of the Creative Commons Attribution (CC BY) license (http:/ / creativecommons.org/licenses/by/4.0/). 